\title{
Extended-spectrum $\beta$-lactamase prevalence and virulence factor characterization of enterotoxigenic Escherichia coli responsible for acute diarrhea in Nepal from 2001 to 2016
}

Katie R. Margulieux ${ }^{1 *}$ (D, Apichai Srijan ${ }^{1}$, Sirigade Ruekit ${ }^{1}$, Panida Nobthai ${ }^{1}$, Kamonporn Poramathikul', Prativa Pandey ${ }^{2}$, Oralak Serichantalergs', Sanjaya K. Shrestha ${ }^{3}$, Ladaporn Bodhidatta ${ }^{1}$ and Brett E. Swierczewski ${ }^{1,4}$

\begin{abstract}
Background: Multidrug-resistant (MDR) Gram-negative bacterial species are an increasingly dangerous public health threat, and are now endemic in many areas of South Asia. However, there are a lack of comprehensive data from many countries in this region determining historic and current MDR prevalence. Enterotoxigenic Escherichia coli (ETEC) is a leading cause of both acute infant diarrhea and traveler's diarrhea in Nepal. The MDR prevalence and associated resistance mechanisms of ETEC isolates responsible for enteric infections in Nepal are largely unknown.

Methods: A total of 265 ETEC isolates were obtained from acute diarrheal samples (263/265) or patient control samples (2/265) at traveler's clinics or regional hospitals in Nepal from 2001 to 2016. Isolates were screened for antibiotic resistance, to include extended spectrum beta-lactamase (ESBL) production, via the Microscan Automated Microbiology System. ETEC virulence factors, specifically enterotoxins and colonization factors (CFs), were detected using multiplex PCR, and prevalence in the total isolate population was compared to ESBL-positive isolates. ESBLpositive isolates were assessed using multiplex PCR for genetic markers potentially responsible for observed resistance.

Results: A total of 118/265 (44.5\%) ETEC isolates demonstrated resistance to $\geq 2$ antibiotics. ESBL-positive phenotypes were detected in 40/265 isolates, with isolates from 2008, 2013, 2014, and 2016 demonstrating ESBL prevalence rates of $1.5,34.5,31.2$, and $35.0 \%$ respectively. No difference was observed in overall enterotoxin characterization between the total ETEC and ESBL-positive populations. The CFs CS2 (13.6\%), CS3 (25.3\%), CS6 (30.2\%), and CS21 (62.6\%) were the most prevalent in the total ETEC population. The ESBL-positive ETEC isolates exhibited a higher association trend with the CFs CS2 (37.5\%), CS3 (35\%), CS6 (42.5\%), and CS21 (67.5\%). The primary ESBL gene identified was bla followed by bla $a_{\mathrm{SHV}-12}(20 \%)$ and bla $a_{\mathrm{CTX}-\mathrm{M}-14}(2.5 \%)$. The beta-lactamase genes bla $a_{\mathrm{TEM}-1}(40 \%)$ and bla $a_{\mathrm{CMY}-2}(2.5 \%)$ were also identified. It was determined that $42.5 \%$ of the ESBL-positive isolates carried multiple resistance genes.

Conclusion: Over 30\% of ETEC isolates collected post-2013 and evaluated in this study demonstrated ESBL resistance. Persistent surveillance and characterization of enteric ETEC isolates are vital for tracking the community presence of MDR bacterial species in order to recommend effective treatment strategies and help mitigate the spread of resistant pathogens.
\end{abstract}

Keywords: ETEC, ESBL, Nepal

\footnotetext{
*Correspondence: katie.margulieux.ctr@afrims.org

'Department of Enteric Diseases, Armed Forces Research Institute of Medical

Sciences, 315/6 Rajvithee Road, Bangkok 10400, Thailand

Full list of author information is available at the end of the article
}

(c) The Author(s). 2018 Open Access This article is distributed under the terms of the Creative Commons Attribution 4.0 International License (http://creativecommons.org/licenses/by/4.0/), which permits unrestricted use, distribution, and reproduction in any medium, provided you give appropriate credit to the original author(s) and the source, provide a link to the Creative Commons license, and indicate if changes were made. The Creative Commons Public Domain Dedication waiver (http://creativecommons.org/publicdomain/zero/1.0/) applies to the data made available in this article, unless otherwise stated. 


\section{Background}

Multidrug-resistant (MDR) Gram-negative bacterial species are an established prominent international public health threat [1]. MDR pathogens have an especially high prevalence in South Asia where bacterial infections are common and antibiotic use is widely unregulated [2-4]. A lack of comprehensive surveillance programs may result in the unchecked spread of MDR Gram-negative bacterial species and their associated resistance mechanisms. Developing countries with an established national surveillance network, such as Nepal, do not have the resources to perform in-depth isolate characterization to comprehensively identify resistance mechanisms carried by MDR bacterial isolates [5-7]. It is imperative that both archived and current bacterial isolates from underdeveloped regions undergo extensive MDR characterization to inform national strategies designed to halt the continuing spread of these dangerous pathogens.

Diarrheagenic Escherichia coli is a ubiquitous presence in the developing world and is responsible for a range of enteric infections [8-10]. Enterotoxigenic E. coli (ETEC) is defined by production of $1-3$ enterotoxins, and is one of the leading causes of both acute infant diarrhea and traveler's diarrhea worldwide, including Nepal [11-14]. ETEC attaches to and colonizes cells in the small intestine along the epithelial surface through the interaction of bacterial colonization factors (CFs) with the intestinal cell wall $[15,16]$. After the establishment of intestinal colonization, the bacterial cells produce heat-labile enterotoxins (LT) and/or heat-stable enterotoxins (STh or STp) that target vital cellular processes $[8,17,18]$. The production of these enterotoxins most commonly results in abdominal cramping and watery diarrhea, with more severe cases also presenting with fever and nausea. ETEC infections are typically self-limiting with resolution of symptoms 3-7 days after initial onset and a recommended treatment strategy of rest and oral rehydration therapy $[8,19]$. In spite of ongoing efforts to develop an ETEC vaccine, no viable vaccine candidates have been produced thus far [20, 21]. ETEC virulence factors, such as enterotoxins and CFs, are potential targets for vaccines or therapeutic candidates, and determination of regional prevalence rates and specific virulence factors may serve to inform the development of globally effective vaccines $[15,18-21]$.

Severe ETEC cases presenting with cholera-like watery diarrhea that do not resolve through oral rehydration therapy may require treatment with antibiotics $[8,10]$. Initial treatment has historically been administration of first-line beta-lactams and quinolones. However, the evolution and global dissemination of multiple classes of antimicrobial resistance mechanisms has led to an increase of MDR ETEC infections that are insensitive to first-line antibiotics [11, 22]. Beta-lactamases and Extended-spectrum $\beta$-lactamases
(ESBLs) confer resistance to a number of antibiotic classes, such as penicillins, extended-spectrum cephalosporins, and monobactams [23, 24]. Global dissemination of these mechanisms has occurred through clonal expansion and/or horizontal transfer of genetic resistance mechanisms between bacterial species [24]. Bacterial pathogens carrying ESBL resistance mechanisms are commonly associated with, and detected in, hospital-acquired infections. However, these antibiotic resistance mechanisms have spread to community-acquired isolates, and are increasingly identified in acute diarrhea and other enteric infections [12, 2530]. ETEC infections are a large cause of acute diarrhea cases in Nepal, but prevalence rates of MDR ETEC isolates, both from a historic or current perspective, are unknown.

The current study determined antibiotic resistance and virulence factors of ETEC isolates previously identified from clinical acute diarrheal samples (263/265) or patient control samples $(2 / 265)$ collected in Nepal between 2001 and 2016. The ETEC isolates were assayed to determine antimicrobial resistance profiles (including ESBL production) and virulence factor characterization, specifically enterotoxins and colonization factors. Antimicrobial resistance studies that encompass retrospective and current clinical isolates are vital to under standing the regional emergence of ESBL producing organisms, the existing treatment challenges, and the potential for ongoing dissemination. This study serves as a thorough investigation of antibiotic resistance in ETEC isolates from acute diarrheal samples in Nepal, and highlights the need for interventions that may address and stem the continual spread of MDR mechanisms in community settings.

\section{Methods}

Bacterial strains, media, and chemicals

A total of 265 ETEC isolates were previously isolated and identified from clinical acute diarrheal samples $(263 / 265)$ or patient control samples $(2 / 265)$ collected from hospitals and travel clinics in Nepal from 2001 to 2016. The isolates were archived for long-term storage at $-20{ }^{\circ} \mathrm{C}$ in Luria Bertani (LB) broth $+20 \%$ glycerol at the Armed Forces Research Institute of Medical Sciences (AFRIMS) in Bangkok, Thailand. The archived ETEC isolates were grown from frozen glycerol stocks on MacConkey agar (MAC) plates overnight at $37{ }^{\circ} \mathrm{C}$. Isolated colonies were re-streaked on tryptic soy agar (TSA) plates, blood agar plates (BAP), or colonization factor agar (CFA) plates in preparation for further phenotypic analysis or DNA isolation.

\section{Antimicrobial susceptibility testing}

All ETEC isolates were screened for ESBL production using the Microscan, Walkaway 40 automated system with Negative Breakpoint Combo 34 panels as per manufacturer's instructions (Beckman Coulter, West Sacramento, CA, USA). 
ESBL-positive isolates were identified by automatic susceptibility testing panel results by assessing bacterial susceptibility to cefotaxime and ceftazidime with or without clavulanic acid. ESBL-positive ETEC isolates were confirmed through disk diffusion assay against beta-lactam combination agents using both cefotaxime $(30 \mu \mathrm{g})$ and ceftazidime $(30 \mu \mathrm{g})$ with or without clavulanic acid $(10 \mu \mathrm{g})$ following Clinical and Laboratory Standards Institute guidelines [31]. A $\geq 5 \mathrm{~mm}$ increase in zone diameter for either antimicrobial agent tested in combination with clavulanate and the zone diameter of the agent when tested along indicated ESBL production.

\section{Multiplex PCR for ETEC virulence factors}

The previously identified and archived ETEC isolates were re-tested to confirm the presence of ETEC enterotoxin genes (lt, sth, and $s t p)$ using multiplex PCR as previously described in detail [32]. ETEC colonization factors (CFA/1, CS1, CS2, CS3, CS4, CS5, CS6, CS7, CS8, CS12, CS13, CS14, CS15, CS17, CS18, CS19, CS20, CS21, and CS22) were identified using multiplex PCR as previously described in detail [32].

\section{Multiplex PCR for ESBL gene identification and DNA sequencing}

ETEC isolates that tested positive for ESBL production were further characterized to determine potential genetic elements responsible for the observed antimicrobial resistance through multiplex PCR as described previously [33]. All PCR primers and conditions used for beta-lactamase or ESBL characterization were listed previously [33]. The genes identified from the multiplex PCR assays were sequenced to determine variant type. Genetic sequencing services were contracted through AITbiotech (Singapore) or First BASE (Selangor, Malaysia). The PCR products were prepared and sent for sequencing according to company instruction. The nucleotide sequences were analyzed with Sequencher software version 5.3 and BLAST software (http://www.Ncbi.nlm.nih.gov/BLAST).

\section{Statistics}

Statistical analyses were performed using GraphPad QuickCalcs. Experimental groups were analyzed using a chi-square with Fisher's exact test with a two-tailed $p$ value of $\leq 0.05$ considered statistically significant.

\section{Results}

\section{Antibiotic resistance characterization of ETEC isolates}

A total of 117/265 (44.1\%) ETEC isolates demonstrated full susceptibility to all antibiotics tested, with an additional 30/265 (11.3\%) resistant to only a single antibiotic tested. The remaining 118/265 (44.5\%) isolates demonstrated resistance to $\geq 2$ antibiotics tested (Table 1). Antibiotic resistance to ampicillin was most common (113/ $265,42.6 \%)$, followed by trimethoprim/sulfamethoxazole
(77/265, 29.1\%), tetracycline (74/265, 27.9\%), and ampicillin/ sulbactam $(32 / 265,12.1 \%)$. A lesser number of isolates were shown to be resistant to ciprofloxacin (15/ $265,5.7 \%$ ) and no isolates showed antibiotic resistance to ertapenem. Of the 118 isolates with increased drugresistance, 40 demonstrated phenotypic production of ESBLs with resistance to the extended-spectrum $\beta$-la ctams cefotaxime (40/40, 100\%), ceftazidime (39/40, 97.5\%), and/or ceftriaxone (35/40, 87.5\%) (Table 1). ESBL-production in all positive ETEC isolates was confirmed through a disk diffusion test. A single isolate from 2008 was positive for ESBL production (1/62, 1.5\%). The remaining ESBL-positive ETEC isolates were collected during 2013 (8/21), 2014 (10/32), and 2016 $(21 / 60)$, resulting in yearly prevalence rates of $34.5,31.2$, and $35.0 \%$, respectively (Table 1 ). Of the ESBL-positive ETEC isolates, the majority were recovered from acute diarrheal samples (39/40, 97.5\%), however, 1/40 (2.5\%) was recovered from a patient control sample.

\section{ETEC enterotoxin gene characterization and prevalence} Detection of the ETEC enterotoxin genes $l t$, sth, and/or stp was performed for all isolates. The enterotoxin gene lt was detected in a total of 132/265 (49.8\%) isolates, sth was detected in a total of $152 / 265$ (57.3\%) isolates, and stp was detected in a total of $72 / 265$ (27.5\%) isolates. Multiple enterotoxin genes were detected in $88 / 265$ (33.2\%) isolates, and enterotoxin gene combinations prevalence are described in Table 2. The enterotoxin combination of sth only was significantly detected less frequently in ESBL-positive isolates compared to ESBLnegative isolates $(15 \%$ vs. $30.9 \% ; p=0.0156)$. No other enterotoxin gene (by total percent detected or by combinations) demonstrated a statistically significant difference in prevalence rates between the two populations.

\section{ETEC CF characterization and prevalence}

CFs were detected in 222/265 (83.8\%) of the total ETEC isolates, and multiple CFs were detected in 162/265 (61.1\%) isolates. CS2 (13.6\%), CS3 (25.3\%), CS6 (30.2\%), and CS21 (62.6\%) were the most prevalent CFs identified in the total ETEC population. The ESBL-positive ETEC isolates showed a trend of higher association with CS2 (37.5\%), CS3 (35\%), CS6 (42.5\%), and CS21 (67.5\%) compared to the total population. The ESBL-positive ETEC population had a statistically significant higher prevalence rate compared to the ESBL-negative population for CS2 (37.5.0\% vs. 9.3\%; $p=0.0002)$. Conversely, the ESBL-negative population had a statistically significant higher prevalence of CS1 compared to the ESBL-positive population (10.2\% vs $0.0 \% ; p=0.0311)$. The multiple CF combinations CS6/CS21 and CS2/CS3/CS21 were the most prevalent in both the total population and ESBL-positive 
Table 1 Total number of ETEC isolates, isolates resistant to $\geq 2$ antibiotics, and isolates that display ESBL-positive phenotypes per year

\begin{tabular}{llll}
\hline Year & Total \# of Isolates & Isolates $R \geq 2$ Antibiotics (\%) & ESBL Positive Isolates (\%) \\
\hline 2001 & 12 & $9(75)$ & 0 \\
2002 & 30 & $5(16.7)$ & 0 \\
2003 & 5 & $3(60)$ & 0 \\
2007 & 34 & $8(23.5)$ & 0 \\
2008 & 62 & $25(40.3)$ & $1(1.5)$ \\
2009 & 8 & $4(50)$ & 0 \\
2012 & 1 & 0 & 0 \\
2013 & 21 & $11(52.4)$ & $8(35.6)$ \\
2014 & 32 & $14(43.8)$ & $10(31.2)$ \\
2016 & 60 & $39(65)$ & $21(35)$ \\
Total & 265 & $118(44.5)$ & $40(15.1)$ \\
\hline
\end{tabular}

population (Table 3). The CF combination CS2/CS3/ CS21 was statistically significantly higher in the ESBL-positive ETEC population when compared to the ESBL-negative ETEC population (25.0\% vs. $7.1 \%$; $p=0.0018)$. No other CFs or CF combinations were statistically significant between the two populations, despite overall higher prevalence trends demonstrated in the ESBL-positive ETEC population for many CFs and CF combinations.

\section{ESBL gene identification}

ESBL-positive ETEC isolates were screened for carriage of known prevalent ESBL and/or beta-lactamase genes using a multiplex PCR assay [33]. The most prevalent ESBL gene detected was bla ${ }_{\mathrm{CTX}-\mathrm{M}}$ group 1 with $32 / 40$ (80\%) of isolates harboring this gene. This gene was further identified as bla $a_{\mathrm{CTX}-\mathrm{M}-15}$ through PCR sequencing analysis (Table 4). Additionally, the ESBL genes $b l a_{\mathrm{SHV}-12}$ and $b l a_{\mathrm{CTX}-\mathrm{M}-14}$ were identified with prevalence rates of $20 \%(8 / 40)$ and $2.5 \%$ (1/40), respectively.

Table 2 Enterotoxin gene detection within total ETEC

\begin{tabular}{lll}
\multicolumn{2}{l}{ population and ESBL-positive population } \\
\hline Enterotoxin(s) & Total $n=265(\%)$ & ESBL Positive $n=40(\%)$ \\
\hline It & $132(49.8)$ & $23(57.5)$ \\
sth & $152(57.3)$ & $21(52.5)$ \\
stp & $73(27.5)$ & $13(32.5)$ \\
Multiple & $88(33.2)$ & $17(42.5)$ \\
Combinations & & \\
It only & $44(16.6)$ & $6(15)$ \\
sth only & $82(30.9)$ & $6(15)$ \\
stp only & $51(19.2)$ & $11(27.5)$ \\
It/sth & $66(24.9)$ & $15(37.5)$ \\
It/stp & $18(6.8)$ & $2(5)$ \\
It $/$ sth/stp & $4(1.5)$ & 0 \\
\hline
\end{tabular}

The beta-lactamase genes $b_{\text {TEM-1 }}(16 / 40,40 \%)$ and bla $a_{\mathrm{CMY}-2}(1 / 40,2.5 \%)$ were also shown to be carried in the ESBL-positive ETEC population. A total of 17/40 (42.5\%) isolates were shown to carry multiple ESBL and/ or beta-lactamase genes (Table 4). Notably, the multiplex PCR screen did not identify any ESBL or beta-lactamase genes in one phenotypically ESBL-positive ETEC isolate. The multiplex PCR assay performed in this study screens for prevalent resistance genes, but is not a comprehensive

Table 3 Colonization factor characterization within total ETEC population and ESBL-positive ETEC population

\begin{tabular}{lll}
\hline Colonization Factor & Total $n=265(\%)$ & ESBL Positive $n=40(\%)$ \\
\hline CFA/1 & $18(6.8)$ & $3(7.5)$ \\
CS1 & $23(8.7)$ & 0 \\
CS2 & $36(13.6)$ & $15(37.5)$ \\
CS3 & $67(25.3)$ & $14(35)$ \\
CS4 & $8(3)$ & 0 \\
CS6 & $80(30.2)$ & $17(42.5)$ \\
CS7 & $5(1.9)$ & 0 \\
CS8 & $11(4.2)$ & 0 \\
CS12 & $6(2.3)$ & $2(5)$ \\
CS13 & $1(0.4)$ & 0 \\
CS14 & $5(1.9)$ & 0 \\
CS17 & $10(3.8)$ & 0 \\
CS20 & $5(1.9)$ & 0 \\
CS21 & $166(62.6)$ & $27(67.5)$ \\
None Detected & $43(16.2)$ & $3(7.5)$ \\
Multiple CFs & $162(61.1)$ & $30(75)$ \\
Combinations & & $12(30)$ \\
CS6/CS21 & $55(20.8)$ & $10(25)$ \\
CS2/CS3/CS21 & $26(9.8)$ & 0 \\
CS1/CS3/CS21 & $22(8.3)$ & \\
\hline
\end{tabular}


Table 4 Determination of ESBL and beta-lactamase gene type

\begin{tabular}{|c|c|c|c|c|c|c|c|c|}
\hline \multirow[b]{2}{*}{ Year } & \multirow[b]{2}{*}{ No. of Isolates } & \multicolumn{7}{|c|}{ No. of Isolates with Gene(s) Detected (\%) } \\
\hline & & bla & bla $a_{\mathrm{CTX}-\mathrm{M}-14}$ & bla $a_{\mathrm{SHV}-12}$ & $b / a_{\mathrm{TEM}-1}$ & bla $a_{C M Y-2}$ & No Genes Detected & Multiple Genes \\
\hline 2008 & 1 & $1(100)$ & 0 & 0 & 0 & 0 & 0 & 0 \\
\hline 2013 & 8 & $8(100)$ & 0 & $1(12.5)$ & $6(75)$ & 0 & 0 & $7(87.5)$ \\
\hline 2014 & 10 & $8(80)$ & $1(10)$ & $1(10)$ & $4(40)$ & 0 & 0 & $4(40)$ \\
\hline 2016 & 21 & $15(71.4)$ & 0 & $6(28.6)$ & $6(28.6)$ & $1(4.8)$ & $1(4.8)$ & $6(23.8)$ \\
\hline Total & 40 & $32(80)$ & $1(2.5)$ & $8(20)$ & $15(37.5)$ & $1(2.5)$ & $1(2.5)$ & $17(42.5)$ \\
\hline
\end{tabular}

investigation of ESBL genes. As such, additional analysis of this isolate may identify the presence of less prevalent or novel ESBL genes.

\section{Discussion}

MDR Gram-negative bacterial pathogens are a global public health threat $[1,6]$. ESBL-producing bacterial strains were first detected in, and were mostly limited to, hospital-associated infections, but began being detected in community-associated infections beginning in the early 2000 's [25, 27, 28, 34]. Initial reports of community-associated ESBL-producing E. coli strains, including reports originating from Nepal, are mainly comprised of pathogens isolated from urinary tract or blood stream infections [3539]. However, community-associated infections isolated from enteric MDR pathogens are being increasingly reported in South and Southeast Asia [8, 11, 12, 22, 26, 30].

ETEC is an enteric pathogen that results in both acute infant diarrhea and traveler's diarrhea [8, 10, 15]. ESBL-producing ETEC may result in treatment failures for infections that were previously easily treatable with first-line antibiotic administration. In the current study, only a single ESBL-positive ETEC isolate was identified from isolates archived in 2001-2009 from Nepal. However, over 30\% of the ETEC isolates collected after 2013 phenotypically display ESBL production. This suggests that ESBL resistance mechanisms in Nepal have expanded relatively recently into community-associated bacterial pathogens, and represents a new threat to both the community as well as international travelers in the region. Notably, international travelers have been shown to be a potential vector for the spread of resistant bacterial pathogens through acquisition during travel, contributing to the global dissemination of MDR enteric pathogens [40]. The combination of established community prevalence and additional spread by infected travelers may contribute to local and global dissemination of ESBL-positive ETEC isolates.

ETEC virulence factors, such as enterotoxins and CFs, are of particular interest as potential targets for infection intervention as vaccine or therapeutic targets $[15,18$, 21]. The expression of enterotoxins and CFs are essential for ETEC colonization of the small intestine and resulting pathogenesis. Blocking bacterial cell adhesion to the small intestine and/or neutralizing enterotoxins results in a limited ETEC infection and significantly reduces infection morbidity $[15,18,21]$. The currently reported prevalence of the enterotoxins LT, STh, and STp in this study were comparative to previous studies reviewed and analyzed by Isidean, et al. [18]. The most prevalent CFs in the current study were CS21, CS6, CS3, and CS2, while the most prevalent CFs in previously conducted studies reviewed by Isidean et al were CFA/1, CS6, and CS21 [18]. Notably, CFA/1 was detected at a lower rate in the current study than previously reported (6.8 vs $20 \%$ ), indicating CFA/1 may not be a priority target for ETEC interventions in South Asia [18]. Overall, the current study suggests vaccines and therapeutics targeting the enterotoxins LT and STh, and the CF's CS21, CS6, CS2, and CS3 would likely be most efficacious against ETEC infections in South Asia. This study demonstrated that these virulence factors are also prevalent in the ESBL-positive ETEC population, a group that is important to target for vaccine efficacy as MDR ETEC continues to emerge and spread throughout the region. It is important that ongoing studies characterizing virulence factors in MDR ETEC populations are performed to determine relevant intervention strategies against currently circulating strains.

Many ESBL genes have been reported as actively circulating in South Asia in hospital- and community-associated infections, including bla $a_{\mathrm{CTX}-\mathrm{M}}$ group 1 and group 9, bla $a_{\mathrm{PER}}$, $b l a_{\mathrm{VEB}}, b l a_{\mathrm{GES}}$, and $b l a_{\mathrm{SHV}}$ [41]. Within the gene family $b l a_{\text {СТХ-М, }} b l a_{\text {СТХ-M-15 }}$ and $b l a_{\mathrm{CTX-M-14}}$ are the most common type of ESBL found worldwide [27, 42]. Aligning with the global findings of gene prevalence, previous studies conducted in Nepal have identified $b l a_{\mathrm{CTX}-\mathrm{M}-15}$ as prevalent in hospital-associated $E$. coli infections, while bla $a_{\text {TEM }}$ and $b l a_{\mathrm{SHV}}$ were also detected at a lower frequencies $[43,44]$. In the current study, bla $a_{\mathrm{CTX}-\mathrm{M}-15}$ was detected in the majority of ESBL-positive ETEC isolates. The genes $b l a_{\mathrm{SHV}-12}$, $b l a_{\mathrm{CTX}-\mathrm{M}-14}, b l a_{\mathrm{TEM}-1}$, and $b l a_{\mathrm{CMY}-2}$ were also identified at lower rates, and multiple resistance genes were detected in $40 \%$ of the characterized isolates. Importantly, ESBL resistance mechanisms are often located on mobile plasmids [42, 45, 46]. As such, enteric ETEC strains that are ESBL-positive may potentially serve as a community reservoir in Nepal for the dissemination of ESBL resistance 
mechanisms via clonal expansion and/or horizontal transfer to other bacterial species that do not result in enteric infections. A large percentage of ETEC isolates identified in the current study contain multiple resistance mechanisms, suggesting that horizontal transfer of ESBL genes is actively occurring within enteric bacterial pathogens. Interestingly, this study identified an ESBL-positive ETEC isolate from a patient control sample, absent of diarrheal symptoms, indicating the established presence of asymptomatic MDR pathogens in the community that may contribute to gene dissemination. Additional studies are necessary to observe the source and spread of ESBL resistance mechanisms in community-associated infections in Nepal.

Limitations of the current study include small sample sizes per year and the lack of clinical patient information. These limitations serve to highlight the need for additional long-term, comprehensive enteric pathogen surveillance to track ongoing MDR emergence and spread in community settings. ESBL-positive $E$. coli often have limited treatment options, such as carbapenem antibiotics. However, the efficacy of these treatment options are compromised by increased prevalence of carbapenemase resistance mechanisms, such as $b l a_{\mathrm{NDM}-1}, b l a_{\mathrm{KPC}}$, and $b l a_{\mathrm{IMP}}$. No carbapenemase-producing ETEC were identified in the current study, but continued surveillance is imperative for tracking if, or more likely when, community-associated MDR ETEC isolates acquire carbapenem-resistance mechanisms in Nepal.

\section{Conclusions}

MDR Gram-negative bacterial species pose a dangerous threat to global public health, including community-associated MDR enteric infections that are increasingly prevalent. The current study demonstrated that ESBL resistance mechanisms have spread to community-associated pathogens in Nepal, with over 30\% of ETEC isolates collected after 2013 demonstrating ESBL production. Both retrospective and recent surveillance studies of ETEC isolates identified from acute diarrheal clinical samples are vital for tracking the community presence of emerging antibiotic resistance mechanisms. Consistent, long-term surveillance may lead to better informed treatment options, alternative therapeutic development, and community-based interventions to mitigate the spread of resistant bacterial strains beyond hospital environments.

\section{Abbreviations \\ AFRIMS: Armed Forces Research Institute of Medical Sciences; \\ CFs: Colonization factors; ESBL: Extended spectrum beta-lactamase; \\ ETEC: Enterotoxigenic Escherichia coli; LT: Heat-labile enterotoxin; \\ MDR: Multidrug resistance; ST: Heat-stabile enterotoxin}

\section{Acknowledgements}

The authors would like to thank Dr. John Crawford, members of the AFRIMS Department of Enteric Diseases, Walter Reed/AFRIMS Research Unit Nepal,
Bharatpur Hospital, Kanti Children's Hospital, Sukraraj Tropical and Infectious Disease Hospital, and CIWEC Hospital and Travel Medicine Clinic for assistance, advice, and helpful discussion throughout the project and during manuscript preparation.

Material has been reviewed by the Walter Reed Army Institute of Research. There is no objection to its presentation and/or publication. The opinions or assertions contained herein are the private views of the author, and are not to be construed as official, or as reflecting true views of the Department of the Army or the Department of Defense.

\section{Funding}

This work was funded by the Armed Forces Health Surveillance Branch -

Global Emerging Infections Surveillance and Response System (AFHSB-GEIS).

The funding source had no role in the design, performance, or interpretation and analysis of this study.

\section{Availability of data and materials}

Not applicable.

\section{Authors' contributions}

KRM and KP performed the experiments presented in this work. KRM and BES wrote the manuscript. KRM, AS, SR, PN, KP, PP, OS, SS, LB, and BES designed the experiments, analyzed the resulting data, and reviewed, revised and approved the final manuscript.

Ethics approval and consent to participate

This study uses isolates from previously approved IRB protocols and does not involve human subjects or human subject information.

\section{Consent for publication}

Not applicable.

\section{Competing interests}

The authors have no competing interests to declare.

\section{Publisher's Note}

Springer Nature remains neutral with regard to jurisdictional claims in published maps and institutional affiliations.

\section{Author details}

${ }^{1}$ Department of Enteric Diseases, Armed Forces Research Institute of Medical Sciences, 315/6 Rajvithee Road, Bangkok 10400, Thailand. ${ }^{2}$ CIWEC Hospital and Travel Medicine Clinic, Kathmandu, Nepal. ${ }^{3}$ Walter Reed/AFRIMS Research Unit Nepal, Kathmandu, Nepal. ${ }^{4}$ Present Address: Bacterial Diseases Branch, Walter Reed Army Institute of Research, Silver Spring, MD, USA.

Received: 20 February 2018 Accepted: 6 July 2018

Published online: 20 July 2018

\section{References}

1. Centers for Disease Control and Prevention. Antibiotic resistance threats in the United States, 2013. 2013. https://www.cdc.gov/drugresistance/threatreport-2013/index.html.

2. Lai CC, Lee K, Xiao Y, Ahmad N, Veeraraghavan B, Thamlikitkul V, Tambyah PA, Nelwan RHH, Shibl AM, Wu J-J, et al. High burden of antimicrobial drug resistance in Asia. J Glob Antimicrob Resist. 2014;2:141-7.

3. Hawkey PM. Prevalence and clonality of extended-spectrum $\beta$-lactamases in Asia. Clin Microbiol Infect. 2008;14:159-65.

4. Jean SS, Hsueh PR. High burden of antimicrobial resistance in Asia. Int J Antimicrob Agents. 2011;37:291-5.

5. Basnyat B, Pokharel P, Dixit S, Giri S. Antibiotic use, its resistance in Nepal and recommendations for action: a situation analysis. J Nepal Health Res Counc. 2015;13:102-11.

6. Ayukekbong JA, Ntemgwa M, Atabe AN. The threat of antimicrobial resistance in developing countries: causes and control strategies. Antimicrob Resist Infect Control. 2017;6:47.

7. Vernet G, Mary C, Altmann DM, Doumbo O, Morpeth S, Bhutta ZA, Klugman KP. Surveillance for antimicrobial drug resistance in under-resourced countries. Emerg Infect Dis. 2014;20:434-41. 
8. Qadri F, Svennerholm A-M, Faruque ASG, Sack RB. Enterotoxigenic Escherichia coli in developing countries: epidemiology, microbiology, clinical features, treatment, and prevention. Clin Microbiol Rev. 2005;18:465-83.

9. Vila J, Saez-Lopez E, Johnson JR, Romling U, Dobrindt U, Canton R, Giske CG, Naas T, Carattoli A, Martinez-Medina M, et al. Escherichia coli: an old friend with new tidings. FEMS Microbiol Rev. 2016:40:437-63.

10. Croxen MA, Law RJ, Scholz R, Keeney KM, Wlodarska M, Finlay BB. Recent advances in understanding enteric pathogenic Escherichia coli. Clin Microbiol Rev. 2013;26:822-80.

11. Pandey P, Bodhidatta L, Lewis M, Murphy H, Shlim DR, Cave W, Rajah R, Springer M, Batchelor T, Sornsakrin S, Mason CJ. Travelers' diarrhea in Nepal: an update on the pathogens and antibiotic resistance. J Travel Med. 2011;18:102-8.

12. Murphy H, Pandey P. Pathogens for travelers' diarrhea in Nepal and resistance patterns. Curr Infect Dis Rep. 2012:14:238-45.

13. Turner SM, Scott-Tucker A, Cooper LM, Henderson IR. Weapons of mass destruction: virulence factors of the global killer enterotoxigenic Escherichia coli. FEMS Microbiol Lett. 2006;263:10-20.

14. Shah N, DuPont HL, Ramsey DJ. Global etiology of travelers' diarrhea: systematic review from 1973 to the present. Am J Trop Med Hyg. 2009;80:609-14.

15. Madhavan TPV, Sakellaris H. Colonization factors of enterotoxigenic Escherichia coli. Adv Appl Microbiol. 2015:90:155-97.

16. Fleckenstein JM, Munson GM, Rasko DA. Enterotoxigenic Escherichia coli: orchestrated host engagement. Gut Microbes. 2013:4:392-6.

17. Sears $\mathrm{CL}$, Kaper JB. Enteric bacterial toxins: mechanisms of action and linkage to intestinal secretion. Microbiol Rev. 1996;60:167-215.

18. Isidean SD, Riddle MS, Savarino SJ, Porter CK. A systematic review of ETEC epidemiology focusing on colonization factor and toxin expression. Vaccine. 2011;29:6167-78

19. Fleckenstein JM, Hardwidge PR, Munson GP, Rasko DA, Sommerfelt $H_{\text {, }}$ Steinsland H. Molecular mechanisms of enterotoxigenic Escherichia coli infection. Microbes Infect. 2010;12:89-98.

20. Zhang W, Sack DA. Progress and hurdles in the development of vaccines against enterotoxigenic Escherichia coli in humans. Expert Rev Vaccines. 2012;11:677-94

21. Zhang W, Sack DA. Current progress in developing subunit vaccines against Enterotoxigenic Escherichia coli-associated diarrhea. Clin Vaccine Immunol. 2015;22:983-91.

22. Tribble DR. Resistant pathogens as causes of traveller's diarrhea globally and impact(s) on treatment failure and recommendations. J Travel Med. 2017:24:S6-S12.

23. Rossolini GM, D'Andrea MM, Mugnaioli C. The spread of CTX-M-type extended-spectrum $\beta$-lactamases. Clin Microbiol Infect. 2008;14:33-41.

24. Bajaj P, Singh NS, Virdi JS. Escherichia coli $\beta$-lactamases: what really matters. Front Microbiol. 2016; https://doi.org/10.3389/fmicb.2016.00417.

25. Kassakian SZ, Mermel LA. Changing epidemiology of infections due to extended spectrum $\beta$-lactamase producing bacteria. Antimicrob Resist Infect Control. 2014;3:9.

26. Kumar P, Bag S, Ghosh TS, Dey P, Dayal M, Saha B, Verma J, Pant A Saxena S, Desigamani $A$, et al. Molecular insights into antimicrobial resistance traits of multidrug resistant enteric pathogens isolated from India. Sci Rep. 2017:7:14468.

27. Pitout JD, Laupland KB. Extended-spectrum $\beta$-lactamase-producing Enterobacteriaceae: an emerging public-health concern. Lancet Infect Dis. 2008;8:159-66.

28. Pitout JD. Enterobacteriaceae that produce extended-spectrum $\beta$-lactamases and AmpC $\beta$-lactamases in the community: the tip of the iceberg? Curr Pharm Des. 2013;19:257-63.

29. Pan H, Zhang J, Kuang D, Yang X, Ju W, Huang Z, Guo J, Li Y, Zhang P, Shi W, et al. Molecular analysis and antimicrobial susceptibility of enterotoxigenic Escherichia coli from diarrheal patients. Diagn Microbiol Infect Dis. 2015:81:126-31.

30. Mendez Arancibia E, Pitart C, Ruiz J, Marco F, Gascón J, Vila J. Evolution of antimicrobial resistance in enteroaggregative Escherichia coli and enterotoxigenic Escherichia coli causing traveller's diarrhoea. J Antimicrob Chemother. 2009;64:343-7.

31. Clinical and Laboratory Standards Institute. Performance standards for antimicrobial susceptiblity testing - 28th edition. Wayne: Clinical and Laboratory Standards Institute; 2017.
32. Rodas C, Iniguez V, Qadri F, Wiklund G, Svennerholm AM, Sjoling A. Development of multiplex PCR assays for detection of enterotoxigenic Escherichia coli colonization factors and toxins. J Clin Microbiol. 2009;47: 1218-20.

33. Dallenne C, Da Costa A, Decre D, Favier C, Arlet G. Development of a set of multiplex PCR assays for the detection of genes encoding important betalactamases in Enterobacteriaceae. J Antimicrob Chemother. 2010;65:490-5.

34. Pitout JD, Nordmann P, Laupland KB, Poirel L. Emergence of Enterobacteriaceae producing extended-spectrum $\beta$-lactamases (ESBLs) in the community. J Antimicrob Chemother. 2005;56:52-9.

35. Baral P, Neupane S, Marasini BP, Ghimire KR, Lekhak B, Shrestha B. High prevalence of multidrug resistance in bacterial uropathogens from Kathmandu, Nepal. BMC Res Notes. 2012:5:38.

36. Khadgi S, Timilsina U, Shrestha B. Plasmid profiling of multidrug resistant Escherichia coli strains isolated from urinary tract infection patients. BMC Res Notes. 2013;5:38

37. Parajuli NP, Maharjan P, Parajuli H, Joshi G, Paudel D, Sayami S, Khanal PR. High rates of multidrug resistance among uropathogenic Escherichia coli in children and analyses of ESBL producers from Nepal. Antimicrob Resist Infect Control. 2017:6:9.

38. Ansari S, Nepal HP, Gautam R, Shrestha S, Neopane P, Gurung G, Chapagain ML. Community acquired multi-drug resistant clinical isolates of Escherichia coli in a tertiary care center of Nepal. Antimicrob Resist Infect Control. 2015:4:15.

39. Sharma AR, Bhatta DR, Shrestha J, Banjara MR. Antimicrobial susceptibility pattern of Escherichia coli isolated from urinary tract infected patients attending Bir hospital. Nepal J Sci Technol. 2013;14:177-84.

40. Arcilla MS, van Hattem JM, Haverkate MR, Bootsma MCJ, van Genderen PJJ, Goorhuis A, Grobusch MP, Lashof AMO, Molhoek N, Schultsz C, et al. Import and spread of extended-spectrum beta-lactamase-producing Enterobacteriaceae by international travellers (COMBAT study): a prospective, multicentre cohort study. Lancet Infect Dis. 2017;17:78-85.

41. Hijazi SM, Fawzi MA, Ali FM, Abd El Galil KH. Prevalence and characterization of extended-spectrum $\beta$-lactamases producing Enterobacteriaceae in healthy children and associated risk factors. Ann Clin Microbiol Antimicrob. 2016;15:3

42. Cantón R, González-Alba JM, Galán JC. CTX-M enzymes: origin and diffusion. Front Microbiol. 2012;3:110

43. Sherchan JB, Hayakawa K, Miyoshi-Akiyama T, Ohmagari N, Kirikae T, Nagamatsu M, Tojo M, Ohara H, Sherchand JB, Tandukar S. Clinical epidemiology and molecular analysis of extended-spectrum-beta-lactamaseproducing Escherichia coli in Nepal: characteristics of sequence types 131 and 648. Antimicrob Agents Chemother. 2015;59:3424-32.

44. Pokhrel RH, Thapa B, Kafle R, Shah PK, Tribuddharat C. Co-existence of $\beta$ lactamases in clinical isolates of Escherichia coli from Kathmandu, Nepal. BMC Res Notes. 2014;7:694.

45. Sidjabat HE, Paterson DL. Multidrug-resistant Escherichia coli in Asia: epidemiology and management. Expert Rev Anti-Infect Ther. 2015;13: 575-91.

46. Carattoli A. Plasmids and the spread of resistance. Int J Med Microbiol. 2013; 303:298-304.

Ready to submit your research? Choose BMC and benefit from:

- fast, convenient online submission

- thorough peer review by experienced researchers in your field

- rapid publication on acceptance

- support for research data, including large and complex data types

- gold Open Access which fosters wider collaboration and increased citations

- maximum visibility for your research: over $100 \mathrm{M}$ website views per year

At BMC, research is always in progress.

Learn more biomedcentral.com/submission 